\title{
Binding Interaction of $\left[\operatorname{Re}\left(\mathrm{H}_{2} \mathrm{O}\right)_{3}(\mathrm{CO})_{3}\right]^{+}$with the DNA Fragment d(CpGpG)
}

Fabio Zobi*, Olivier Blacque, Roland K. O. Sigel and Roger Alberto

\section{Contents}

\section{Materials and Methods}

Figure S1. Time dependent evolution of $\left[{ }^{1} \mathrm{H}\right]-\mathrm{NMR}$ resonances for the reaction of $\mathbf{1}$ with $\mathrm{CpGpG}$.

Figure S2. Changes in $\left[{ }^{1} \mathrm{H}\right]-\mathrm{NMR}$ spectrum of $\mathbf{2}$ at different $\mathrm{pH}^{*}$ values.

Figure S3. $\mathrm{pH}$ dependence of the $\left[{ }^{1} \mathrm{H}\right]-\mathrm{NMR}$ resonances of adduct 2 between 7.6 and $8.3 \mathrm{ppm}$.

Figure S4. IR spectrum of the microcrystalline solid obtained from the reaction of 1 with CpGpG.

Figure S5. MS spectrum (negative mode) of 2.

Table S1. Atomic coordinates of preliminary optimized model of $\left[\mathrm{Re}\left(\mathrm{H}_{2} \mathrm{O}\right) \mathrm{d}(\mathrm{CpGpG})(\mathrm{CO})_{3}\right]^{-}(\mathbf{2})$.

\footnotetext{
*To whom correspondence should be addressed. E-mail: fzobi@aci.uzh.ch
} 


\section{Materials and Methods}

All reagents and solvents were purchased from standard sources and used as received. A sample of 5'-CpGpG-3' was purchased from Eurogentec and used as received.

$\left[\mathbf{E t}_{4} \mathbf{N}\right]_{2}\left[\operatorname{ReBr}_{3}(\mathbf{C O})_{3}\right](\mathbf{1})$. Under $\mathrm{N}_{2}$. Finely ground $\left(\mathrm{Et}_{4} \mathrm{~N}\right) \mathrm{Br}(10.5 \mathrm{~g}, 50 \mathrm{mmol})$ was heated to 80 ${ }^{\circ} \mathrm{C}$ in $300 \mathrm{ml}$ of diglyme and suspension evacuated and purged with $\mathrm{N}_{2}$ several times. $\operatorname{ReBr}(\mathrm{CO})_{5}(10$ $\mathrm{g}, 24,6 \mathrm{mmol}$, finely ground) was added as a solid and the reaction mixture heated to $115^{\circ} \mathrm{C}$ for 15 h. The mixture was allowed to cool down to RT and the colourless solid filtered off washed with $\mathrm{CH}_{2} \mathrm{Cl}_{2}$ and dried. Yield $17.9 \mathrm{~g}, 95 \%$.

IR Spectroscopy. IR spectra were recorded on a Perkin-Elmer BX II spectrometer from $\mathrm{KBr}$ pellets.

NMR spectroscopy: Complex 2 was prepared in situ in $200 \mu \mathrm{L} 99.999 \% \mathrm{D}_{2} \mathrm{O}$ in a Shigemi tube. $\left[{ }^{1} \mathrm{H},{ }^{1} \mathrm{H}\right]-\mathrm{NOESY}$ spectra were recorded on a Bruker AV700 MHz spectrometer equipped with a CPTXI z-axis pulsed-field gradient cryoprobe, subsequently processed with XWINNMR (Bruker), and analyzed using Sparky (http://www.cgl.ucsf.edu/home/sparky/). $\left[{ }^{31} \mathrm{P}\right]-\mathrm{NMR}$ spectra were recorded on a Bruker $500 \mathrm{MHz}$ Avance spectrometer.

Calculation of $\mathbf{p} \boldsymbol{K}_{\mathbf{a}}$ value: $\mathrm{pH}$ titrations of $\mathbf{2}$ were performed in $99.999 \% \mathrm{D}_{2} \mathrm{O}$ by using $\mathrm{NaOD}$ and $\mathrm{DCl}$ solutions. $0.4 \log$ units were added to the $\mathrm{pH}$ meter reading to obtain $\mathrm{pD}$ values. ${ }^{1}$ The change in chemical shift of $\mathrm{C} 1 \mathrm{H} 6, \mathrm{G} 2 \mathrm{H} 8$, and $\mathrm{G} 3 \mathrm{H} 8$ was plotted versus $\mathrm{pD}$ and fit with a Levenberg-Marquard non-linear least squares procedure taking one $\mathrm{pKa}$ value into account. ${ }^{2}$ The chemical shift changes of $\mathrm{C} 1 \mathrm{H} 6$ was fit yielding $\mathrm{p} K_{\mathrm{a}, \mathrm{C} 1 \mathrm{H} 6}=5.79 \pm 0.14$ valid for $\mathrm{D}_{2} \mathrm{O}$. This value was transformed $^{2}$ to the corresponding value in water giving $\mathrm{p} K_{\mathrm{a}, \mathrm{H} 2 \mathrm{O}}=5.27 \pm 0.14(1 \sigma)$. 
[1] a) P. K. Glasoe, F. A. Long, J. Phys. Chem. 1960, 64, 188-190. b) R. Lumry, E. Smith, L., R. R. Glantz, J. Am. Chem. Soc. 1951, 73, 4330-4340.

[2] R. K. O. Sigel, M. Sabat, E. Freisinger, A. Mower, B. Lippert, Inorg. Chem. 1999, 38, 14811490.

[3] R. B. Martin, Science 1963, 139, 1189-1203.

\section{Theoretical Calculations}

The preliminary structure simulation was performed with a Spartan '06 program version 1.1.0. The model, based on the NMR data of 2, was chosen such that the carbonyl groups of G1 and G2 are oriented towards a bound $\mathrm{H}_{2} \mathrm{O}$ molecule so as to maximize $\mathrm{H}$-bonding interactions. Three intermolecular hydrogen-hydrogen interactions (G2H8-G3H8, G2H8-C1H6 and G3H8-C1H6) have been restrained to about $3.0 \pm 0.15 \AA$ to reach the given structure. The Spartan-included basic minimizer has been used on several plausible starting geometries and we retained the energetically favoured system as a model to illustrate our NMR results. 

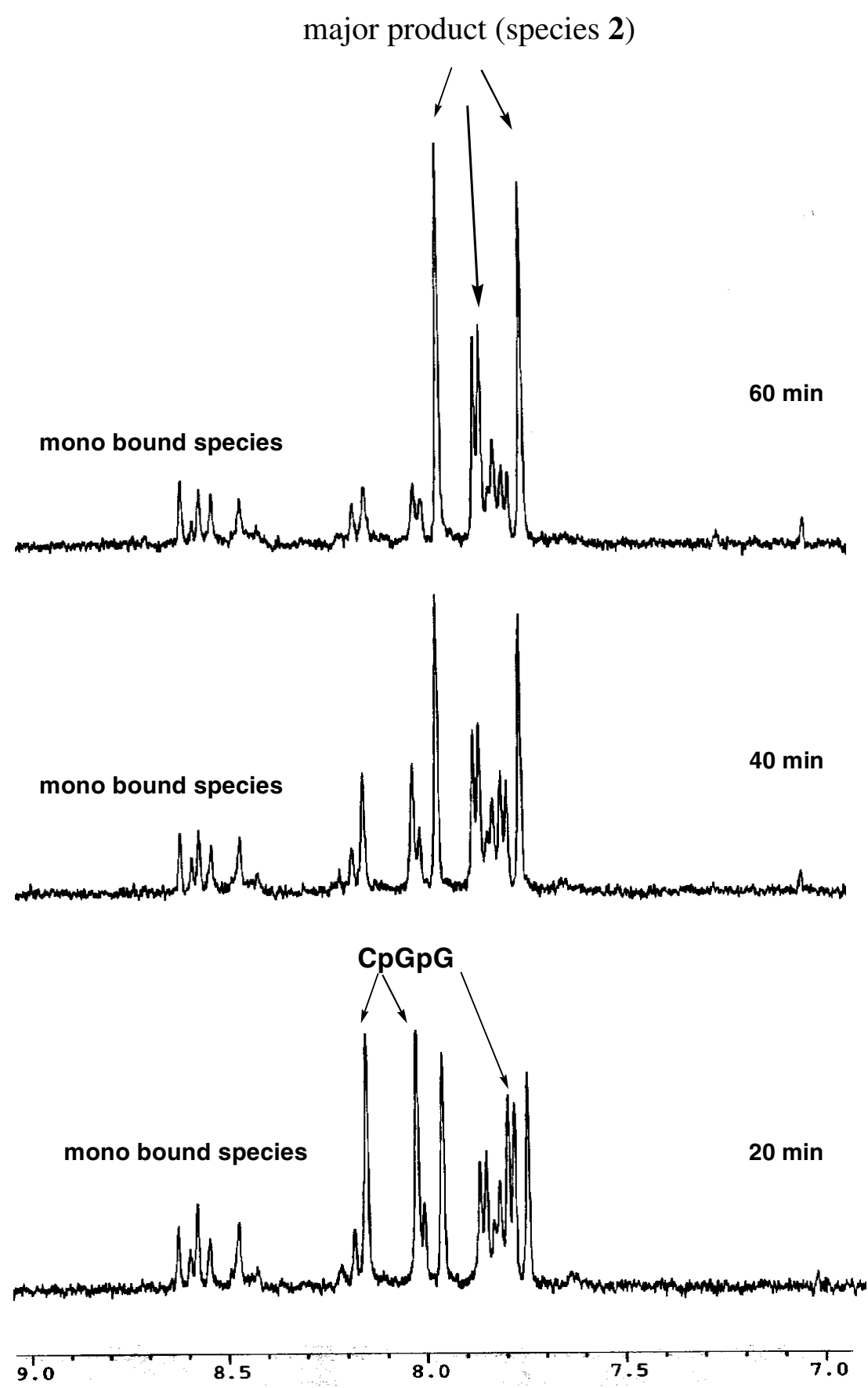

Figure S1. Time dependent evolution of $\left[{ }^{1} \mathrm{H}\right]-\mathrm{NMR}$ resonances between 7 and $9 \mathrm{ppm}$ for the reaction of 1 with $\mathrm{CpGpG}$ (conditions: $0.547 \mathrm{mg} \mathrm{CpGpG}$ in $0.75 \mathrm{~mL} \mathrm{D}_{2} \mathrm{O}, 37^{\circ} \mathrm{C}$ ). 

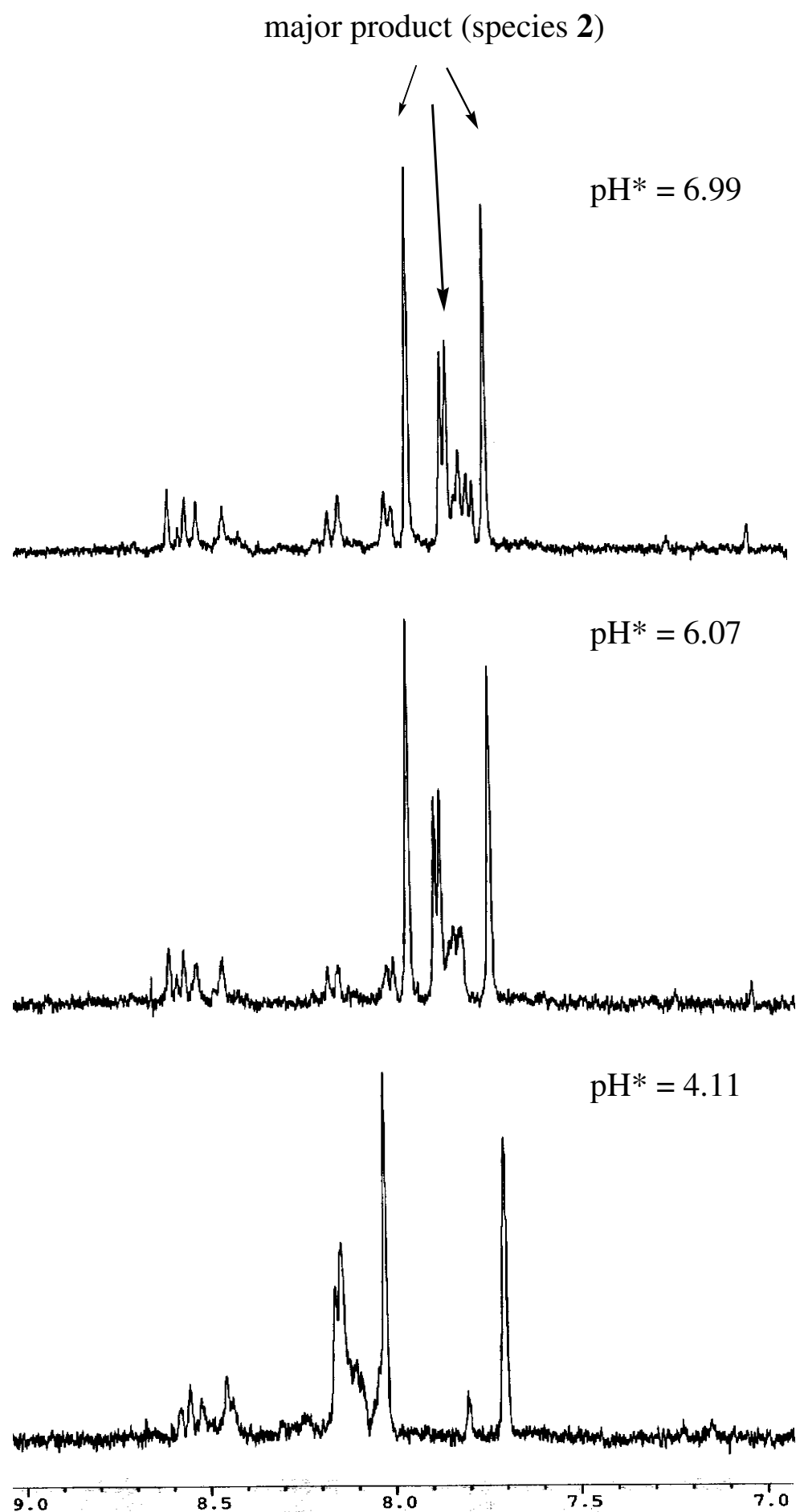

Figure S2. Changes in $\left[{ }^{1} \mathrm{H}\right]$-NMR spectrum obtained after 80 min incubation of $\mathrm{CpGpG}$ with 1eq. of 1 at different $\mathrm{pH}^{*}$ values (conditions: $0.547 \mathrm{mg} \mathrm{CpGpG}$ in $0.75 \mathrm{~mL} \mathrm{D}_{2} \mathrm{O}, 37^{\circ} \mathrm{C}$ ). 


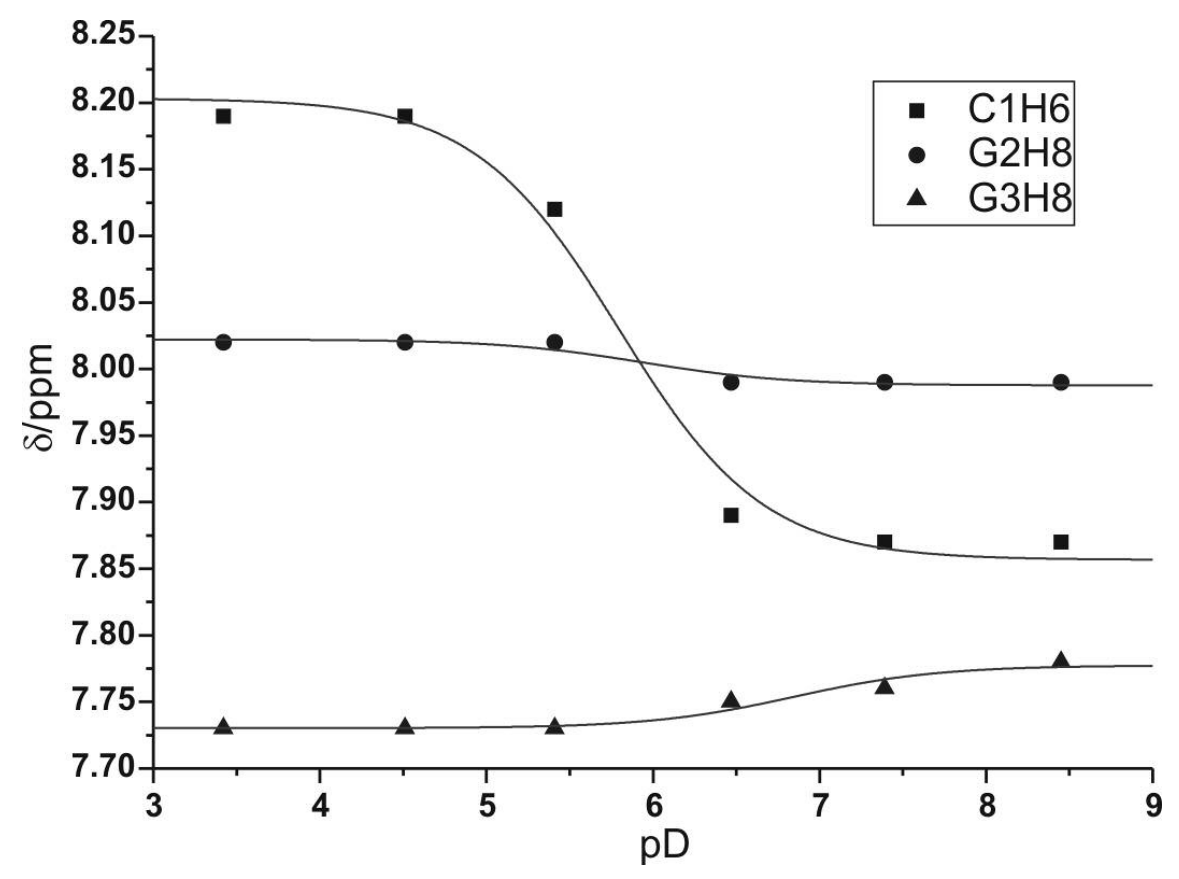

Figure S3. $\mathrm{pH}$ dependence of the $\left[{ }^{1} \mathrm{H}\right]-\mathrm{NMR}$ resonances of adduct 2 between 7.6 and $8.3 \mathrm{ppm}$. The - indicate G3H8, the $\boldsymbol{c} \mathrm{C} 1 \mathrm{H} 6$ and the $\Delta \mathrm{G} 2 \mathrm{H} 8$.

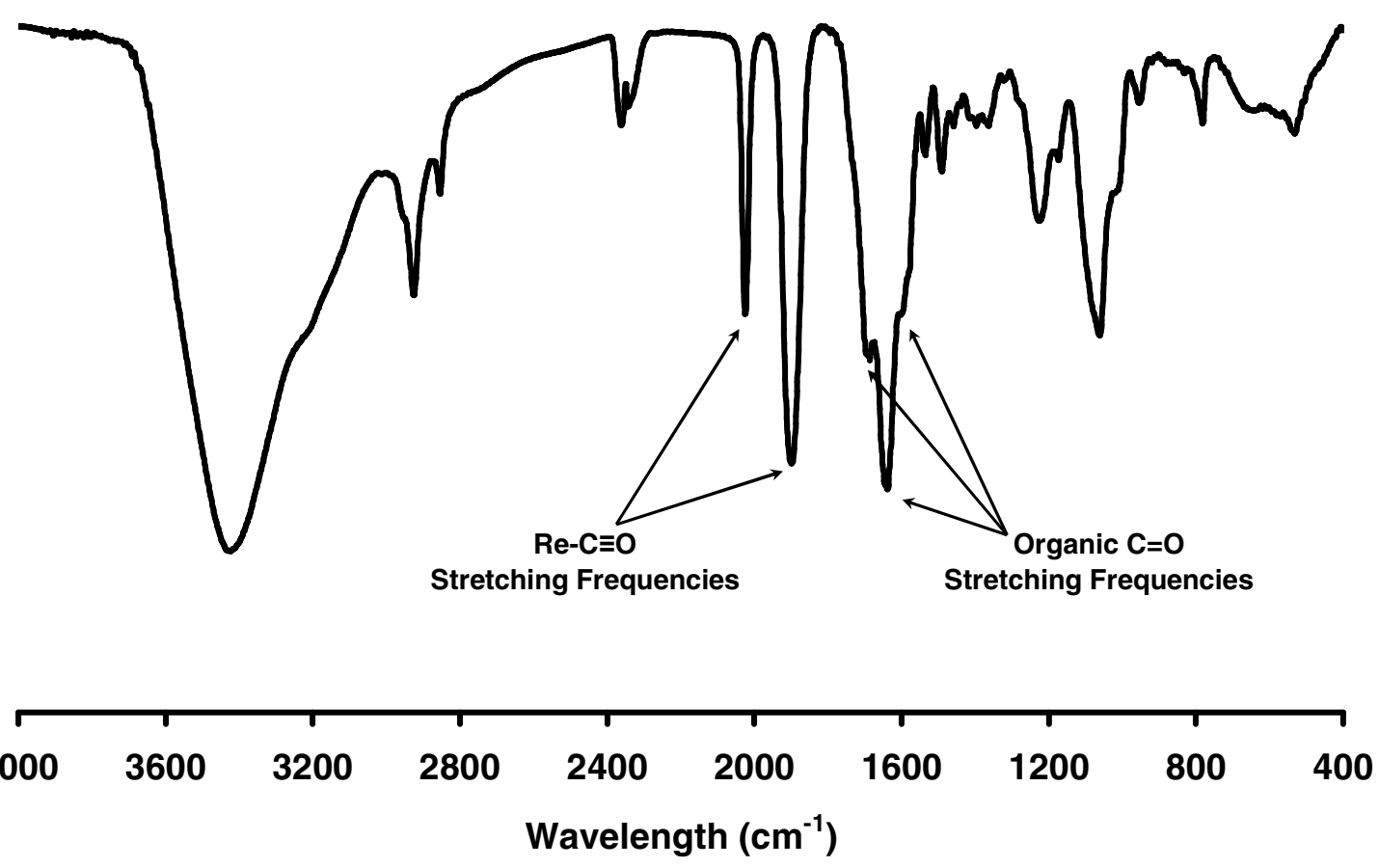

Figure S4. IR spectrum (in $\mathrm{KBr}$ ) of the microcrystalline solid obtained from the reaction of 1 with CpGpG. 


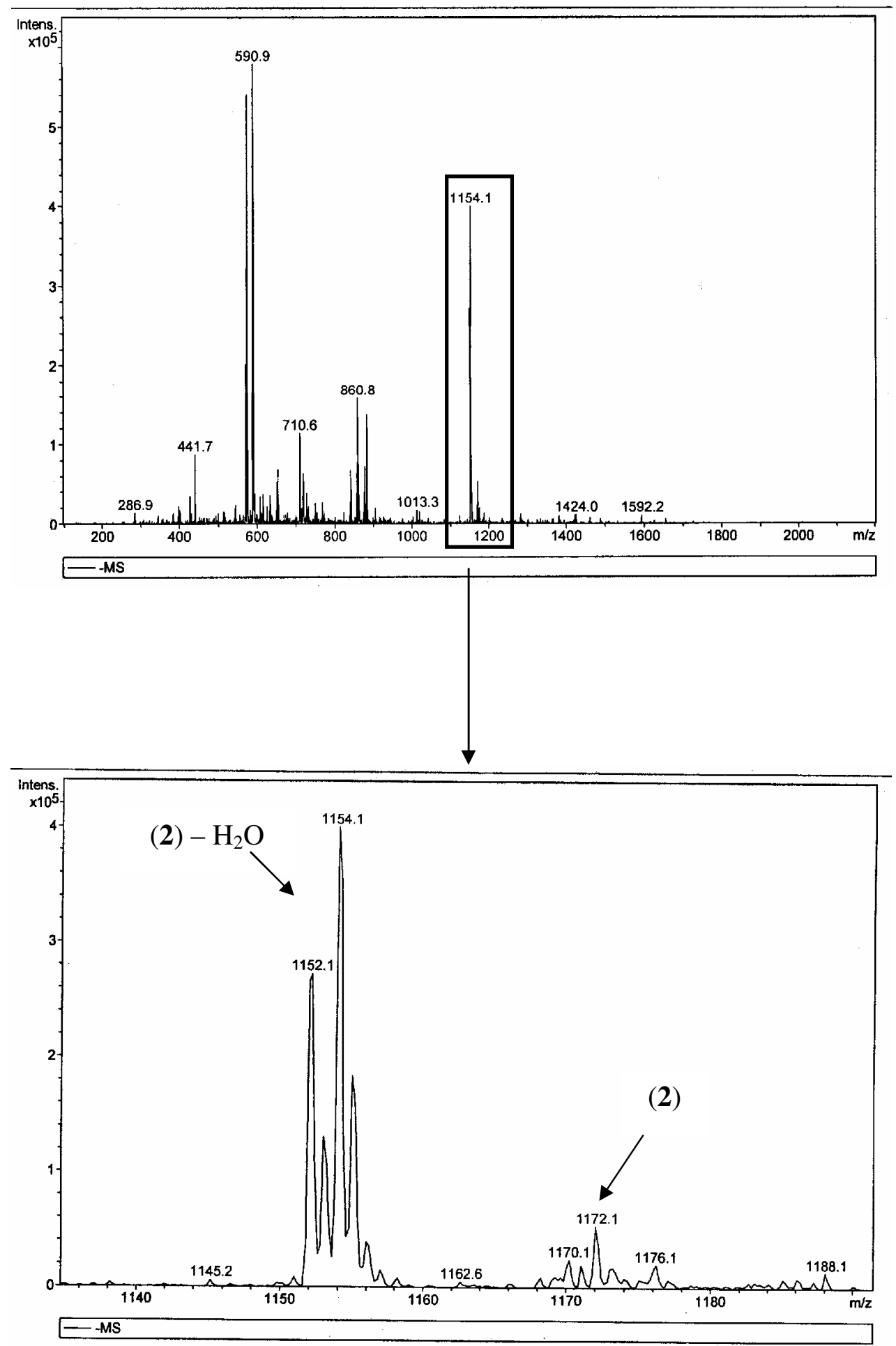

Figure S5. MS spectrum (negative mode) of 2 . 
Table S1. Atomic coordinates of preliminary optimized model of $\left[\operatorname{Re}\left(\mathrm{H}_{2} \mathrm{O}\right) \mathrm{d}(\mathrm{CpGpG})(\mathrm{CO})_{3}\right]^{-}(\mathbf{2})$.

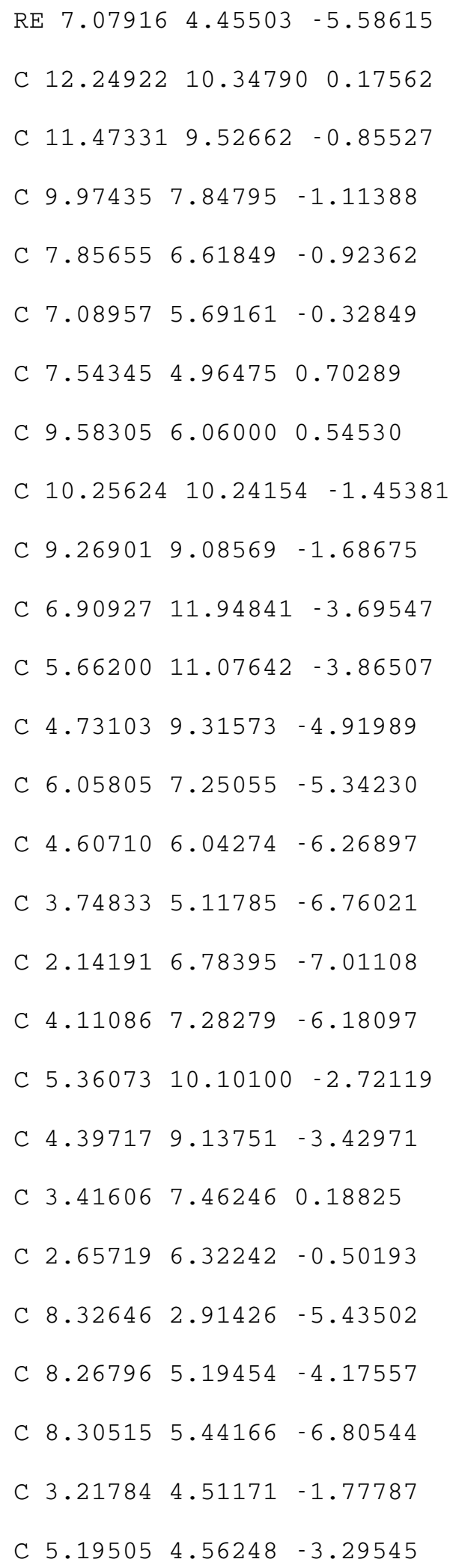




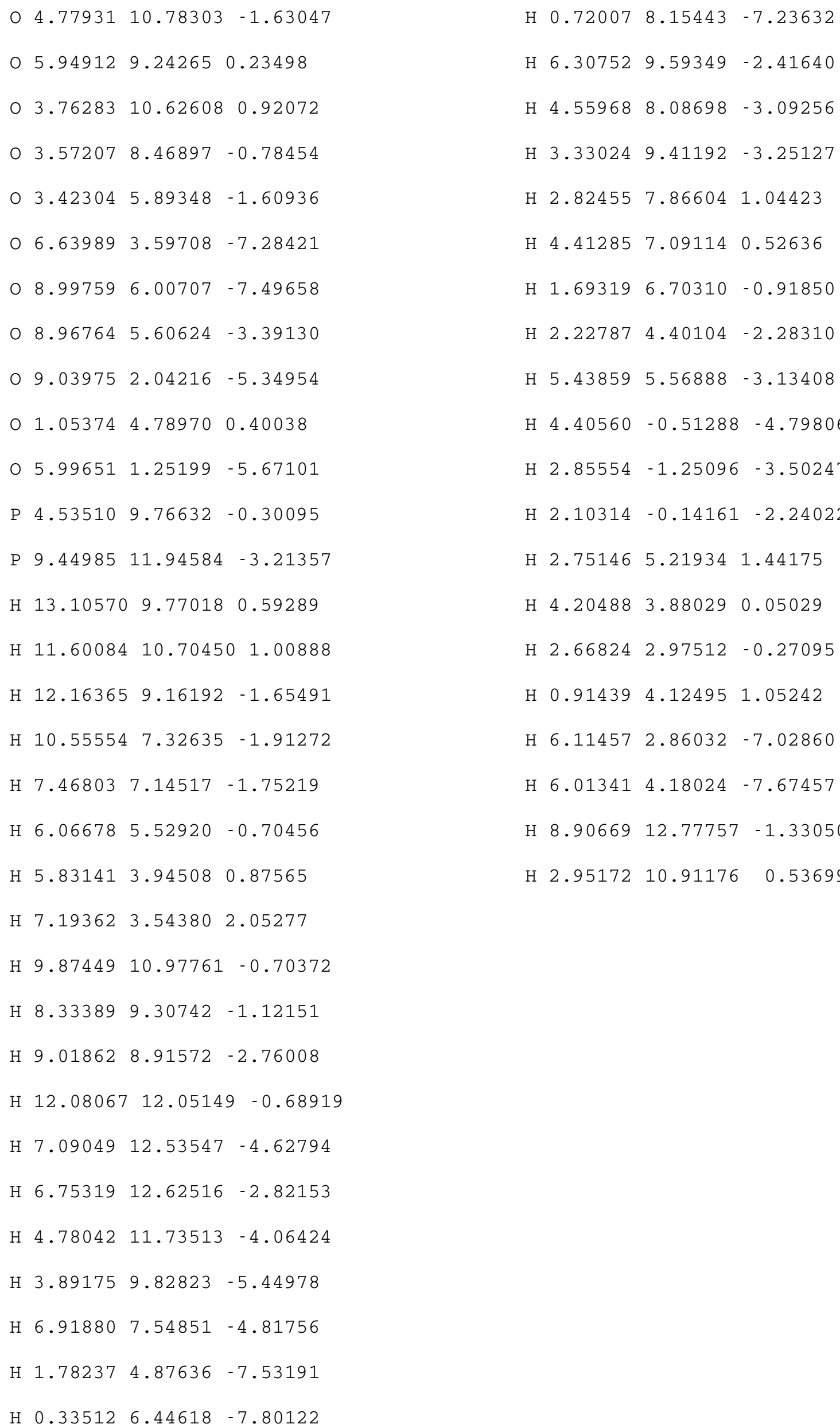

